\title{
Cluster Analysis and Principal Component Analysis Application in Primary Health Care Institutions
}

\author{
Zhuoshi $\mathrm{Li}^{1, \mathrm{a}}$, Mei Wang ${ }^{2, \mathrm{~b}}$, Fugui Zhu ${ }^{3, \mathrm{c}}$, Hang Chen ${ }^{4, \mathrm{~d}}$ \\ 1,2,3 Jilin Agricultural University, Changchun, Jilin,130018, China \\ ${ }^{4}$ Institute of Scientfic and Technical Information of Jilin, Jilin,130033, China \\ aleezs643@sina.com, ${ }^{b} 499360221 @ q q . c o m,{ }^{c}$ leezs036@foxmail.com
}

Keywords: cluster analysis; principal component analysis; primary health care institutions

\begin{abstract}
In this paper, we use the principal component analysis and cluster analysis on the development of a combination of medical institutions in the region to analyze. In order to analyze the number of organizations from all regions, the number of beds and so on, At first the cluster analysis method for our various regions medical and health institutions system classification. Finally using the principal component analysis to explore the various regions of the recommendations put forward some development problems of health care institutions.
\end{abstract}

\section{Introduction}

Primary health care institutions mainly refers to the smallest administrative division level medical institutions. With economic development, the level of grass-roots medical services have made great progress. Which is closely linked to its development of China's medical and health institutions. The health authorities in most areas of high prevalence, but the level of medical and health institutions as well as small parts can not achieve the requirements of people, so we want our medical institutions in various regions of the grass-roots research, select the need to increase development efforts in the region. To improve the level of primary health care institutions develop a force [1].

Different classes between samples cluster analysis is something with property classified as a place of thought, the data sample packet combining several classes or clusters, so that property in the same class between samples is substantially the same, and properties vary greatly, as cluster analysis, one can distinguish between densely and sparsely populated areas, the overall situation of mutual understanding and classification mode data attributes[2].

Principal component analysis is a multivariate statistical analysis. It is a way to extract the number of variables into a few variables integrated multivariate statistical analysis method, which has many variables associated relationship, divided into several linear combinations of variance to measure the amount of information contained in the combination, most informative as the first principal component, using the same method to select multiple main ingredient[3].

\section{Cluster Analysis Applications in the Primary Medical Health Institutions}

Firstly, cluster analysis[4] is used for hierarchical clustering and principal component extracted data using principal component analysis, in accordance with the cluster analysis results reflect the primary component for the development of provincial and base area municipal health care institutions for analysis as shown in table 1.

For a given data clustering software application Matlab[6], first input data to calculate the distance between samples using Euclidean distance method, then the distance between the shortest distance defined class. in accordance with hierarchical clustering, the distance between the class with the shortest distance method, the results of the most long-distance method, the average distance obtained by the same method as shown in table 2 . 
Table 1 Medical and health organization data of various provinces and cities (unit: ten thousand )

\begin{tabular}{|c|c|c|c|c|c|}
\hline $\begin{array}{l}\text { Provinces and } \\
\text { Cities }\end{array}$ & $\begin{array}{l}\text { Number of } \\
\text { institution }\end{array}$ & $\begin{array}{c}\text { Number of } \\
\text { bed }\end{array}$ & Number of staff & $\begin{array}{l}\text { number of } \\
\text { treatment }\end{array}$ & $\begin{array}{c}\text { Number of } \\
\text { Inpatient }\end{array}$ \\
\hline 1. Beijing & 0.8837 & 0.4745 & 5.7084 & 5902.4 & 3.6 \\
\hline 2.Tianjin & 0.4095 & 0.7023 & 2.2438 & 3573.9 & 12.1 \\
\hline 3.Hebei & 7.7177 & 6.9143 & 19.0636 & 26630.9 & 167.7 \\
\hline 4.Shanxi & 3.8443 & 3.9956 & 10.6332 & 7431.4 & 62 \\
\hline 5.Neimenggu & 2.2009 & 2.4543 & 6.7255 & 5524.8 & 38.7 \\
\hline 6.Liaoning & 3.4249 & 3.6464 & 10.0016 & 9361.8 & 73 \\
\hline 7.Jilin & 1.8804 & 2.1577 & 6.6326 & 5295.6 & 33.9 \\
\hline 8.Heilongjiang & 1.9470 & 2.8422 & 8.1287 & 5882.4 & 62.2 \\
\hline 9.Shanghai & 0.4379 & 1.7389 & 4.7289 & 9259.8 & 10.5 \\
\hline 10.Jiangsu & 2.8888 & 6.9516 & 19.2076 & 24596.8 & 168.3 \\
\hline 11.Zhejiang & 2.8939 & 2.6852 & 12.7410 & 22478.7 & 28.8 \\
\hline 12.Anhui & 2.1812 & 5.7826 & 13.5525 & 15529.4 & 179 \\
\hline 13.Fujian & 2.6374 & 2.9910 & 9.3236 & 10051.9 & 124.9 \\
\hline 14.Jiangxi & 3.8369 & 4.9312 & 11.4113 & 13091.9 & 245.3 \\
\hline 15.Shandong & 6.6462 & 12.5877 & 32.5600 & 41339.1 & 345.7 \\
\hline 16.Henan & 6.7252 & 10.1176 & 28.0477 & 35193.7 & 331.1 \\
\hline 17.Hubei & 3.4063 & 6.8293 & 15.6935 & 20008.4 & 238.1 \\
\hline 18.Hunan & 5.7177 & 8.6069 & 16.4844 & 14862.2 & 348.4 \\
\hline 19.Guangzhou & 4.4585 & 5.9457 & 21.4410 & 35910.7 & 196.1 \\
\hline 20.Guangxi & 3.3257 & 5.0264 & 12.5210 & 14490.5 & 247.3 \\
\hline 21.Hainan & 0.4839 & 0.5885 & 1.8920 & 2285.3 & 10 \\
\hline 22.Chongqing & 1.7310 & 4.1107 & 7.8560 & 8352 & 177.2 \\
\hline 23.Sichuan & 7.4215 & 12.2678 & 23.5351 & 28478.3 & 520 \\
\hline 24.Guizhou & 2.6264 & 3.7815 & 7.8283 & 7788 & 220.3 \\
\hline 25.Yunnan & 2.1887 & 4.4427 & 8.6135 & 12300.3 & 144.9 \\
\hline 26.Tibet & 0.6412 & 0.2583 & 1.3832 & 677.3 & 2.9 \\
\hline 27.Shanxi & 4.5889 & 3.3677 & 10.5034 & 9623.1 & 80.9 \\
\hline 28.Gansu & 2.5631 & 3.1891 & 6.9915 & 8349.4 & 68.4 \\
\hline 29.Qinghai & 0.5658 & 0.5103 & 1.6162 & 1199.2 & 18.7 \\
\hline 30.Ningxia & 0.3904 & 0.2832 & 1.2405 & 1566.1 & 5.9 \\
\hline
\end{tabular}

Table 2 The expression data of principal component coefficients

\begin{tabular}{ll}
\hline Classification & Provinces and Cities \\
\hline First Class & Shandong, Henan, Sichuan \\
Second Class & Hebei, Hunan, Guangzhou \\
& Shanxi, Neimenggu, Liaoning, Jilin, Heilongjiang, Anhui, Fujian, \\
Third Class & Jiangxi, Hubei, Guangxi, Chongqing, Guizhou, Yunnan, Shaanxi, \\
& Gansu, Jiangsu, Zhejiang, Xinjiang, Shanxi \\
Fourt Class & Shanghai, Beijing, Tianjin, Ningxia, Shanghai, Tibet \\
\hline
\end{tabular}

\section{Principal component analysis in a healthcare analysis application}

Principal component analysis of the data, obtained characteristic value, contribution rate and cumulative contribution rate [5] as shown in table 3.

Table 3 Characteristic value and contribution rate

\begin{tabular}{ccc}
\hline Characteristic & Contribution rate & $\begin{array}{c}\text { Cumulative } \\
\text { contribution rate }\end{array}$ \\
\hline 4.4263 & 88.5261 & 88.5261 \\
0.3331 & 6.6618 & 95.1879 \\
0.1890 & 3.7800 & 98.9679 \\
0.0416 & 0.8321 & 99.0800 \\
0.0100 & 0.0200 & 100.1000 \\
\hline
\end{tabular}

In the table, the contribution rate of the first principal component reached $88.5261 \%$ cumulative contribution rate of the first two principal components exceeds 95\%, so I chose the first two principal 
components analysis on it. The first two the primary components of the coefficient data variables shown in table 4.

Table 4 The expression data of principal component coefficients

\begin{tabular}{ccc}
\hline the standard variation & principal component 1 & principal component 2 \\
\hline institution & 0.4388 & -0.6003 \\
bed & 0.4661 & 0.2023 \\
staff & 0.4640 & -0.3206 \\
treatment & 0.4385 & 0.0329 \\
inpatient & 0.4274 & 0.7031 \\
\hline
\end{tabular}

According to table 4 to write the first two principal components of the expression:

$$
\begin{aligned}
& y_{1}=0.4388 x_{1}^{*}+0.4661 x_{2}^{*}+0.4640 x_{3}^{*}+0.4385 x_{4}^{*}+0.4274 x_{5}^{*} \\
& y_{2}=-0.6003 x_{1}^{*}+0.2023 x_{2}^{*}-0.3206 x_{3}^{*}-0.0329 x_{4}^{*}+0.7031 x_{5}^{*}
\end{aligned}
$$

The first principal component $y_{1}$ from the expression, it has a similar loads, a description of each standard $y_{1}$ on the importance of variation are similar, can be considered the first principal component reflects the primary health care sector in each respective standard variable overall levels .

The second the primary component $y_{2}$ from the expression, it has higher levels of negative load variation on the standard $x_{5}^{*}, x_{1}^{*}$ has a higher positive load. Description second component reflects the contrast of two aspects, one clinic visits reflects, on the one hand reflects hospitalized people.

\section{Summary}

Difference of provinces grassroots medical institutions in the region, can be roughly divided into four different types. According to the results of the main components, the first principal component reflects the consolidation of staffing levels, the first two categories, Shandong, Henan, Sichuan, Hebei, Hunan, Guangzhou is the most populated province, level of economic development is also in the upper reaches, appropriate medical organization, staffing, clinic visits on at a high level. More than a dozen provinces in the third category of the population size in the middle level, the scale of the development of medical and health institutions is relatively small compared to some of the first class. The fourth category is more complicated, both big cities such as Beijing, Shanghai, there are Qinghai, Tibet, so the relative economic conditions are not good province. Beijing, Shanghai is divided into the fourth category is actually very easy to understand, and their grass-roots population ratio compared to other provinces is relatively small, demand so people are generally accepted by non-primary care, so was in the fourth class. Like Hunan, Hubei, Anhui, Guangxi, so more of the population of the provinces are divided in the fourth category a bit unreasonable, their economic situation is relatively less prominent, relatively scarce health care institutions, will appear this situation.

\section{Acknowledgements}

The Youth Foundation of Jilin Agricultural University （201328）

Jilin Province Innovation and Entrepreneurship Students Training Program Project

Jilin Agricultural University Undergraduate Science and Technology Innovation Fund Project

\section{References}

[1] Yuanwen Luo and Shixing Zhang, The key problems and countermeasures of medical insurance for urban workers.Guangxi Economic Management Institute Journal . Vol.1(2010),p.59-61.

[2] Zhuohua Zhou and Wennan Chen,Cluster Analysis in Investment in Securities.Chongqing University Journal. Macmillan.Vol.25(2002),p.14-16. 
[3] Zhenhai Yang,Applied Mathematical Statistics,first ed.,Beijing University of Technology Press.Beijing,2005.

[4] Xiaoyan Li. Application of principal component analysis in public health indicators in the evaluation of the rural,China Health Economics. Vol.5(2007),p.41-46.

[5] Tao Jiang,Ming Gao,The main ingredient of Chongqing mountain yellow nutrient characteristics and cluster analysis,. Southwest Agricultural Sciences Journal.Vol.21(2008),p.36-39.

[6] Yanke Bao and Na Li,Matlab Mathematical Statistics and Data Processing, third ed.,Northeastern University Press,Shenyang,2008. 